\title{
Long-term exposure to PM2.5 and Children's lung function: a dose-based association analysis
}

\author{
Sai Li ${ }^{1 \#}$, Suzhen Cao ${ }^{1 \#}$, Xiaoli Duan ${ }^{1}$, Yaqun Zhang ${ }^{2}$, Jicheng Gong ${ }^{3}$, Xiangyu Xu ${ }^{1}$, Qian Guo ${ }^{1}$, Xin Meng ${ }^{3}$, \\ Mcswain Bertrand ${ }^{1}$, Junfeng Jim Zhang ${ }^{3,4,5,6}$
}

${ }^{1}$ School of Energy and Environmental Engineering, University of Science and Technology Beijing, Beijing, China; ${ }^{2}$ Gansu Provincial Design and Research Institute of Environmental Science, Lanzhou, China; ${ }^{3}$ Beijing Innovation Center for Engineering Science and Advanced Technology, State Key Joint Laboratory for Environmental Simulation and Pollution Control, College of Environmental Sciences and Engineering, And Center for Environment and Health, Peking University, Beijing, China; ${ }^{4}$ Duke Kunshan University, Kunshan, China; ${ }^{5}$ Nicholas School of the Environment and Duke Global Health Institute, Duke University, Durham, USA; ${ }^{6}$ Guangzhou Institute of Respiratory Health, The First Affiliated Hospital of Guangzhou Medical University, Guangzhou, China

Contributions: (I) Conception and design: JJ Zhang, J Gong, X Duan; (II) Administrative support: Y Zhang, S Cao; (III) Provision of study materials or patients: S Cao, Y Zhang, X Duan; (IV) Collection and assembly of data: S Li, X Xu, Q Guo; (V) Data analysis and interpretation: S Li, Q Guo, J Gong, X Meng; (VI) Manuscript writing: All authors; (VII) Final approval of manuscript: All authors.

"These authors contributed equally to this work and as co-first authors.

Correspondence to: Xiaoli Duan, PhD. University of Science and Technology Beijing, 30 Xueyuan Road, Beijing 100083, China. Email: jasmine@ustb.edu.cn.

Background: The current literature is still not consist regarding the effect of long-term exposure to PM2.5 and children's lung function, partly due to inadequate or inaccurate exposure assessment. In this study, we aim to investigate the associations between long-term exposure to PM2.5, estimated as average daily dose (ADD), and lung function in school-age children.

Methods: We recruited 684 participants of 7-12 years old from the city of Lanzhou located in northwestern China. Participants underwent spirometric tests for lung function and responded to a questionnaire survey. Detailed information about individual air exposure and personal information were collected, including length of school hours, home address, age, gender, etc. Combining the spatial distribution of PM2.5 concentrations in the past 5 years and individual time-activity data, we estimated annual ADD for 5 years preceding the lung function tests and 5-year average $\mathrm{ADD}$, respectively. We used multiple linear regression models to examine the associations between ADD values and lung function, controlling for a range of individual-level covariates. Results: The 5-year average ADD among all the participants was $50.5 \mu \mathrm{g} / \mathrm{kg}$-d, with higher values estimated for children living in the urban area than the suburban area, for boys than girls, and for children whose parents received a lower education attainment. We found that a $1 \mu \mathrm{g} / \mathrm{kg}-\mathrm{d}$ increment in ADD of PM2.5 was associated with a $10.49 \mathrm{~mL}$ (95\% CI: -20.47, -0.50) decrease in forced vital capacity (FVC) and a $7.68 \mathrm{~mL}(95 \% \mathrm{CI}:-15.80,-0.44)$ decrease in forced exploratory volume in 1 second $\left(\mathrm{FEV}_{1}\right)$. Among the annual ADDs estimated for the preceding 5 years, the immediate past year prior to lung function measurement had the greatest effect on lung function. The effect was greater in girls than in boys. We found no associations between annual exposure of PM2.5 (instead of ADD) and lung function when defined concentration was used as an exposure variable.

Conclusions: Long-term PM2.5 exposure, when estimated as exposure dose averaged over a year or longer, was associated with statistically significant reductions in FVC and FEV1 in children of elementaryschool age. Future studies may consider the use of individual-level dose estimates (as opposed to exposure concentrations) to improve the dose-response assessment.

Keywords: Children; average daily dose (ADD); fine particulate matter (fine PM); lung function

Submitted Mar 28, 2020. Accepted for publication Aug 04, 2020.

doi: $10.21037 /$ jtd-19-crh-aq-007

View this article at: http://dx.doi.org/10.21037/jtd-19-crh-aq-007

(C) Journal of Thoracic Disease. All rights reserved.

f Thorac Dis 2020;12(10):6379-6395 I http://dx.doi.org/10.21037/jtd-19-crh-aq-007 


\section{Introduction}

Ambient particulate matter (PM) with an aerodynamic diameter $\leq 2.5 \mu \mathrm{m}\left(\mathrm{PM}_{2.5}\right)$, capable of penetrating and depositing in the deep lung, constitutes a large size fraction of PM present in modern urban atmospheres (1-3). $\mathrm{PM}_{2.5}$ has been associated with a range of adverse respiratory health effects include respiratory diseases and changes in lung function $(4,5)$. Lung function is a noninvasive measure of respiratory health and has been commonly used in previous studies to assess the respiratory health effects of air pollution (6-8). The lack of a fully developed lung function during childhood is a risk factor for many diseases like chronic obstructive pulmonary diseases (9) in adulthood. Unfortunately, children are more susceptible than adults to the respiratory effects of air pollution largely due to the fact that children's lung is still under development (10-12). Moreover, children generally inhale more PMs due to higher metabolic rate and high physical activity level as well as their time-activity patterns often leading to increased exposure (13).

Exposure to ambient PM has been associated with reduced lung function in many studies $(3,14-16)$. For example, in school-age children living in southern California, exposure to $\mathrm{PM}_{2.5}$ was associated with clinically and statistically significant deficits in the forced expiratory volume in 1 second $\left(\mathrm{FEV}_{1}\right)$; and the growth of $\mathrm{FEV}_{1}$ was slower in more polluted (higher $\mathrm{PM}_{2.5}$ ) communities (17). In fact, most studies (18-21) on the association between $\mathrm{PM}_{2.5}$ exposure and lung function to date were carried out in populations exposed to certain concentration levels of air pollution. While some studies reported an association between higher air pollution exposure and reduced lung function in school-age children $(22,23)$, other studies did not find such an association $(24,25)$. The inconsistency may be due to differences in $\mathrm{PM}_{2.5}$ composition and/or exposure misclassification that has been common in cohort and population studies in which individual differences in exposure were not considered. To overcome the problem of exposure misclassification, assessment of exposure dose can more accurately reflect the dose-response relationship. Estimating dose requires integrating exposure concentration, behavior patterns and individual inhalation rate that depends on activity state (26).

In the present study, we aim to use dose estimates to assess the dose-response, instead of conventional exposureresponse relationships, between long-term $\mathrm{PM}_{2.5}$ exposure and lung function in school-age children. To estimate dose, we used a spatiotemporal model to estimate $\mathrm{PM}_{2.5}$ concentrations for main micro-environments (residence, school, and in-transit routes between school and residence) over the 5 -year period preceding lung function measurements. Multi-year dose estimates were used to identify the time window most influential to lung function.

\section{Methods}

\section{Study site and population}

The study was conducted in children living in Lanzhou, the capitol city of Gansu Province, comprised of five municipal districts of Chengguan, Qilihe, Xigu, Anning, and Honggu, covering an area of approximately $13,085 \mathrm{~km}^{2}$, with a population of about $3,729,600$ in 2017 when this study was conducted (27). Lanzhou is an important industrial base and broad transportation hub in northwest China and is an important node city in the Silk Road economic belt. Lanzhou is located in the transition zone between monsoon climate and non-monsoon climate. Recent rapid urbanization has resulted in a significant increase in the number of vehicles and factories. This, coupled with Lanzhou's valley topography, make Lanzhou among one of the most polluted Chinese cities. Across the city, the heterogeneity in industrial development and the varying topology result in spatial variability in ambient pollution levels.

Two primary schools were selected in the urban and suburban area for this study, with most students living nearby. In totality, 401 students from the urban area and 590 from the suburban area, with an aged range from 6 to 12 , were recruited randomly from the aforementioned schools. The Ethics Committee of Biomedicine Research, Duke Kunshan University, approved the study and written consent was obtained from the parents. The questionnaire on child's behavior patterns, health state and environmental and other risk factors was completed on requested. The lung function measurements were conducted among healthy children from grade 1 to grade 6, about 192 from urban and 492 from the suburban areas, from November 272017 to December 292017.

The study was conducted in accordance with the Declaration of Helsinki (as revised in 2013). This study was reviewed and approved by the Committee on Ethics of Biomedicine Research, Duke Kunshan University, Jiangsu (No. FWA00021580). All patients enrolled completed the informed consent form. 


\section{Questionnaire survey}

We used a questionnaire adapted from the American Thoracic Society (ATS) Epidemiologic Standardization Project questionnaire on respiratory symptoms and illnesses (28). We also collected additional information on household environmental conditions. The information is classified into the following categories: (I) indoor environment like per-person living area, type of fuel used for cooking, type of kitchen ventilation devices, passive smoking exposure, renovation, dampness and mold, use of air purifiers, air freshener, mosquito-repellent and incense stick, and indoor ventilation and duration; (II) parental health and socioeconomic status like whether parents had doctor-diagnosed asthma and bronchitis, parental education attainment, and parental occupation; (III) early life factors like maternal smoking during pregnancy and the first year after birth, duration of exclusive breastfeeding, and whether child was born prematurely; (IV) children's respiratory health histories like whether child had doctor-diagnosed asthma, bronchitis, and/or allergic rhinitis; (V) information on nutrition and exercise in children, including frequency of fruit and vegetable intake and type and frequency of exercise.

The questionnaire was administered with children's parents prior to the lung function measurements. Only the children whose parents returned a completed questionnaire were included in the lung function measurements.

\section{Lung function measurements}

Lung function measurement were performed using calibrated spirometers (Spiro-lab New, MIR, Italy) following the ATS guidelines for spirometry (29). Children were measured in the standing position inside an airconditioned room with stable air circulation. Body height and weight were measured immediately before test and input in the spirometer to automatically obtain child's predicted lung function. Spirometric lung function was assessed in terms of the four representative indicators, i.e., forced vital capacity (FVC, $\mathrm{mL}$ ), the forced expiratory volume in one second $\left(\mathrm{FEV}_{1}, \mathrm{~mL}\right)$, peak expiratory flow (PEF, $\mathrm{mL} / \mathrm{s}$ ) and the $\mathrm{FEV}_{1} / \mathrm{FVC}$ ratio (\%). Values were also expressed as a percentage of the predicted value (observed value/predicted value $\times 100$ ) for the participant's age, height, weight and gender, using previously established equations (built in the spirometers) (30). For each participant, the spirometry test was repeated for up to five times until acceptable, reproducible flow volume loops were obtained. Each participant was given once lung function test during the study phase. Between one test and the next, the device evaluates the repeatability of the following parameters: repeatable when the difference between the two highest values was $\leq 150 \mathrm{~mL}$ for $\mathrm{FVC}, \leq 150 \mathrm{~mL}$ for $\mathrm{FEV}_{1}$, and $\leq 10 \%$ for PEF. Acceptable spirograms were defined as smooth flow-volume curve without artefacts, and satisfactory exhalation with forced expiratory duration $>6 \mathrm{~s}$ ( $3 \mathrm{~s}$ for children younger than 10 years). If the difference between the two largest FVC readings was within $150 \mathrm{~mL}$, the test was concluded. The highest acceptable values of $\mathrm{FVC}$ and $\mathrm{FEV}_{1}$ were used for statistical analysis.

\section{Exposure assessment}

In this study, a validated $\mathrm{PM}_{2.5}$ concentration modeling method, namely timely structure adaptive modeling (TSAM) (31) was employed to simulate the $\mathrm{PM}_{2.5}$ concentrations (January 2013 to December 2017) at $10 \mathrm{~km}$ spatial resolution. After that, a geostatistical interpolation approach (i.e., Ordinary Kriging) was applied to map the $1 \mathrm{~km}$ spatial resolution $\mathrm{PM}_{2.5}$ concentrations $(32,33)$. Generally, the structure of a TSAM model can be simply defined as Eq. [1], containing dependent variable $\left(\mathrm{PM}_{2.5}\right.$ concentration) and three types of explanatory factors (satellite-retrieved Aerosol Optical Depth (AOD), pollutant emissions and dispersion conditions).

$$
\mathrm{PM}_{2.5} \sim \mathrm{AOD}+\text { Emissions }+ \text { Dispersion }
$$

Where $\mathrm{PM}_{2.5}$ indicates the dependent variable of $\mathrm{PM}_{2.5}$ concentration; AOD is the satellite measurement indirectly representing the $\mathrm{PM}_{2.5}$ concentrations, collected from Atmosphere Archive and Distribution System (AADS, https://ladsweb.nascom.nasa.gov/search/index.html); emissions are the factors related to industrial smoke and dust, vehicle exhaust and surface dust, such as land use type (e.g., built-up, forest, grass, water), road level and so on; Dispersion factors mainly include meteorological and topographical conditions influencing the $\mathrm{PM}_{2.5}$ dispersion such as wind speed, relative humidity, elevation etc.

In order to evaluate the exposure level of individuals, we divided the exposure scenarios into three parts: school, residence and in-transit routes between school and residence. The calculation formula is as follows:

$$
\mathrm{C}=\frac{\Sigma\left(C_{i} \times T_{i}\right)}{24}
$$


in which $\mathrm{C}$ was the average individual exposure level of outdoor $\mathrm{PM}_{2.5}\left(\mu \mathrm{g} / \mathrm{m}^{3}\right), \mathrm{C}_{i}$ was the average concentration of outdoor $\mathrm{PM}_{2.5}\left(\mu \mathrm{g} / \mathrm{m}^{3}\right)$ in this place during this period $(\mathrm{i}=1,2,3), \mathrm{T}_{i}$ the length of time (h) the child stayed at the site ( $i=1,2,3)$. In our study, we set the time spent at home as 15.5 hours daily $\left(\mathrm{T}_{1}=15.5\right)$, the time spent in school was 6.5 hours daily $\left(T_{2}=6.5\right)$ and the time spent on the routes between residence and school was 2 hours daily $\left(\mathrm{T}_{3}=2\right)$. Then we deduced outdoor $\mathrm{PM}_{2.5}$ annual average from 2013-2017.

Since the main exposure route for human exposure to $\mathrm{PM}_{2.5}$ is inhalation, we further estimated the average daily doses (ADD, $\mu \mathrm{g} / \mathrm{kg}-\mathrm{d}$ ) of each child using Equation [3], according to the recommended exposure assessment models in the U.S. Exposure Factors Handbook EPA (34).

$$
A D D_{\text {inh }}=\frac{C \times I R \times E T \times E F \times E D}{B W \times A T}
$$

In which $\mathrm{C}$ is subject-level outdoor $\mathrm{PM}_{2.5}\left(\mathrm{~g} / \mathrm{m}^{3}\right)$ averaged over a defined period (5-yr average or annual average from 2013-2017), IR was the inhalation rates considering gender and age ( $\mathrm{m}^{3} /$ hour), ET was the exposure time (hour/day), EF was the exposure frequency (day/year), ED was the exposure duration (year), BW was the body weight $(\mathrm{kg})$ and AT was the average exposure time (day). The exposure time related to age of children and their BW were obtained through the questionnaire. The other exposure parameters, such as IR were obtained from Exposure Factors Handbook of Chinese Population (children 6-17 years) (35). All the parameters in Equation [3] were specific to the age at which exposure was estimated.

\section{Covariates and effect modifiers}

In our statistical models, a lung function indicator was the main dependent variables, whereas $\mathrm{PM}_{2.5}$ concentration or dose (ADD) was the independent variable and other questionnaire-derived variables were covariates. Variables related to individual characteristics of children included age, school location, gender, whether preterm birth, allergy status, nutrition intake, and physical exercise. "Asthma in past year", "Pneumonia in past year" and "Allergy in past year" refers to that the child had any of these three ailments in the last year. Nutrition related variables were constructed from frequencies of eating vegetables, fruit, dairy product, fish, high-fat and caloric products.
Information about nutrition was grouped according to the Dietary guidelines for Chinese residents (36). Physical exercise variable was based on the information on frequency of exercise and whether child sweated after exercise. We defined parental education and occupation as measures of socioeconomic status and parental history of asthma as a potential effect modifier. Non-manual laborer was similar to the so-called "white collar worker", such as teacher, doctor, businessperson, clerk and housewife, whereas manual laborer was like the so-called "blue collar worker", such as factory worker, construction worker, building cleaning worker and farmer. Children's exposure to indoor air pollution was measured by questionnaire survey such as parental smoking, kitchen style, solid fuel use, ventilation condition, fuel for heating in winter, air purifier use, keeping pets, and room having mold condition. Fuel such as coal, firewood for cooking and heating were defined as solid fuels, whereas clean fuel referred to electricity, natural gas, and liquefied petroleum gas or marsh gas. Finally, the recent history of the children's infection of respiratory diseases, in addition to preterm birth status and breast-feeding status were considered as covariates.

\section{Statistical analysis}

Data analyses were conducted in 684 participants comprised of 371 boys and 313 girls. We used lung function parameters (outcome variables) as dependent variables to analyze their response to $\mathrm{PM}_{2.5}$ exposure. Univariate summary statistics and distributional plots were examined for all variables. We used analysis of variance (ANOVA) for bivariate analysis to explore the distribution of $\mathrm{PM}_{2.5}$ exposure and ADD among other potential confounders. We performed 'screening' analyses in multivariate linear regressions to select covariates that either changed the main effect estimate by $>10 \%$ by including them or showed a $\mathrm{P}$ value $<0.1$ for the regression coefficients. We also conducted subgroup analyses stratified by gender to evaluate the potential modifying effects.

We examined the association between ADD of $\mathrm{PM}_{2.5}$ and lung function, considering each parameter separately. The models included a linear function of ADD and all covariates listed above. The results are presented as estimated changes $(\beta)$ of lung function parameters per 1 unit increase in $\mathrm{PM}_{2.5}$ ADD and $95 \%$ confidence interval. Statistical analyses were conducted using $\mathrm{R}$ version 3.4.3. 


\section{Results}

\section{Description of the population}

This study integrated children's behavior (time-activity) patterns into ambient $\mathrm{PM}_{2.5}$ concentration to estimate average daily exposure dose (ADD) for each child. The baseline characteristics of schoolchildren by covariate are present in Table 1. There are twice as many children in the suburbs $(71.9 \%)$ as in the urban $(28.1 \%)$. Almost half of the children were girls. Children were between 7 to 12 years old, although the majority (72\%) of them were in the age group of 8-10 years.

Within each covariate shown in Table 1, we conducted a simple $t$-test to compare average $\mathrm{PM}_{2.5}$ or ADD across the categories. We found that suburban children have significantly lower $\mathrm{PM}_{2.5}$ concentration and ADD than urban children. Boys had significantly higher ADD than girls (but not $\mathrm{PM}_{2.5}$ ), mainly due to higher inhalation rate for boys. Compared to the oldest age group ( $>10$ years old), the youngest group ( $<8$ years old) had the lower $\mathrm{PM}_{2.5}$ but higher ADD. We listed indoor air quality related variables (parental smoking, kitchen style, cooking fuel, kitchen ventilation, heating in winter, heating fuel, and air fresher use) in the table to show their distributions. Given $\mathrm{PM}_{2.5}$ and ADD were solely based on ambient (outdoor) $\mathrm{PM}_{2.5}$ concentrations, comparing $\mathrm{PM}_{2.5}$ or $\mathrm{ADD}$ within each of these variables did not provide any "causal" insights. Similarly, ADD values or $\mathrm{PM}_{2.5}$ concentrations for other covariates are compared without a causal inference. These comparisons showed the following results.

Children who characterized with solid cook fuel use, mother's education below senior high school, mother had asthma, fruit frequency below reference showed significant higher $(\mathrm{P}<0.05)$ exposure to $\mathrm{PM}_{2.5}$. Moreover, children who were characterized with parental smoking, opened kitchen, no ventilation use, coal for heating, dairy frequency below reference presented significant $(\mathrm{P}<0.001)$ higher individual exposure to $\mathrm{PM}_{2.5}$, compared to the reference group. Of the children living in urban area, father's education below senior high school, mother's education below senior high school, fruit frequency below reference showed significant $(\mathrm{P}<0.05)$ higher of ADD of $\mathrm{PM}_{2.5}$.

\section{$P M_{2.5}$ exposure and lung function}

Summary statistics of the distributions of the long-term $\mathrm{PM}_{2.5}$ averaged over defined periods [2013-2017] and lung function variables measured in 2017 are provided in
Table S1. Because of a lack of home addresses or errors in latitude and longitude resolution, in total the $\mathrm{PM}_{2.5}$ data of 613 children was available for further regression analysis. The 5-year average personal $\mathrm{PM}_{2.5}$ concentrations had a mean of $48.1 \mu \mathrm{g} / \mathrm{m}^{3}$, and a range of $43.8-69.1 \mu \mathrm{g} / \mathrm{m}^{3}$ across 613 subjects. Average personal 5-year averaged ADD was $50.5 \mu \mathrm{g} / \mathrm{kg}-\mathrm{d}$, ranging from 26.3 to $76.2 \mu \mathrm{g} / \mathrm{kg}-\mathrm{d}$. Mean $( \pm \mathrm{SD}) \mathrm{FVC}$ to predict (\%), $\mathrm{FEV}_{1}$ to predict (\%), PEF to predict $(\%), \mathrm{FEV}_{1} / \mathrm{FVC}$ were $104( \pm 10.7), 102( \pm 9.7), 77$ $( \pm 0.8), 91( \pm 0.3)$, respectively.

Univariate analysis of lung function was showed in Table 2. As expected, height, weight, body mass index (BMI) and age of children were significantly and positively associated with $\mathrm{FVC}, \mathrm{FEV}_{1}$ and PEF. Mean lung function variables were lower among girls than boys for FVC $(\beta=-172.75 \mathrm{~mL}, \mathrm{P}<0.0001), \mathrm{FEV}_{1}$ $(\beta=-134.69 \mathrm{~mL}, \mathrm{P}<0.0001)$ and $\operatorname{PEF}(\beta=-399.07 \mathrm{~mL}$, $\mathrm{P}<0.0001)$. Children sleeping alone in a bedroom or alone in bed had significantly higher FVC, FEV ${ }_{1}$ and $\mathrm{PEF}$ than children living in a shared bedroom or shared bed. Having pets $(\beta=-101.89 \mathrm{~mL}, \mathrm{P}=0.0454)$ and using air fresher $(\beta=-89.98 \mathrm{~mL}, \mathrm{P}=0.0243)$ was significantly and negatively associated with FVC. Father's occupation of nonmanual laborer was significantly and positively associated with FVC $(\beta=102.68, P=0.0088)$ and $\mathrm{FEV}_{1}(\beta=77.13$, $\mathrm{P}=0.0231)$. Children sweating more after sports activities had significantly higher FVC $(\beta=112.26 \mathrm{~mL}, \mathrm{P}=0.0022)$, $\mathrm{FEV}_{1}(\beta=83.92 \mathrm{~mL}, \mathrm{P}=0.0077)$ and $\mathrm{PEF}(\beta=173.13 \mathrm{~mL}$, $\mathrm{P}=0.0342)$.

\section{Association of lung function with ADD of $P M_{2.5}$}

The results of individual average daily exposure dose of $\mathrm{PM}_{2.5}$ with relation to lung function are shown in Table 3. In general, the ADD representing long-term (5-year average) exposure dose of $\mathrm{PM}_{2.5}$ had statistically significant negative associations with $\mathrm{FVC}, \mathrm{FEV}_{1}$ and $\mathrm{PEF}$, respectively. For the crude model of adjusting no covariates, a 1-unit increase in $\mathrm{ADD}$ of long-term $\mathrm{PM}_{2.5}$ exposure was significantly associated with $27.08 \mathrm{~mL}$ (95\% CI: -32.41 to $-21.75, \mathrm{P}<0.0001)$ decrease in FVC, $23.65 \mathrm{~mL}(95 \%$ $\mathrm{CI}:-28.30$ to $-19.00, \mathrm{P}<0.0001)$ decrease in $\mathrm{FEV}_{1}$ and $31.16 \mathrm{~mL} / \mathrm{s}$ (95\% CI: -44.04 to $-18.28, \mathrm{P}<0.0001$ ) decrease in PEF. No significant association was observed for $\mathrm{FEV}_{1} / \mathrm{FVC}$. Adjustment for potential confounding variables showed in Table 1 , resulted in attenuations in effect estimates for FVC and $\mathrm{FEV}_{1}$ without changing the statistical significance. However, 
Table 1 Subject characteristics and their $\mathrm{PM}_{2.5}$ exposures measured as 5-year averages from 2013-1017 for both exposure concentration and average daily dose (ADD)

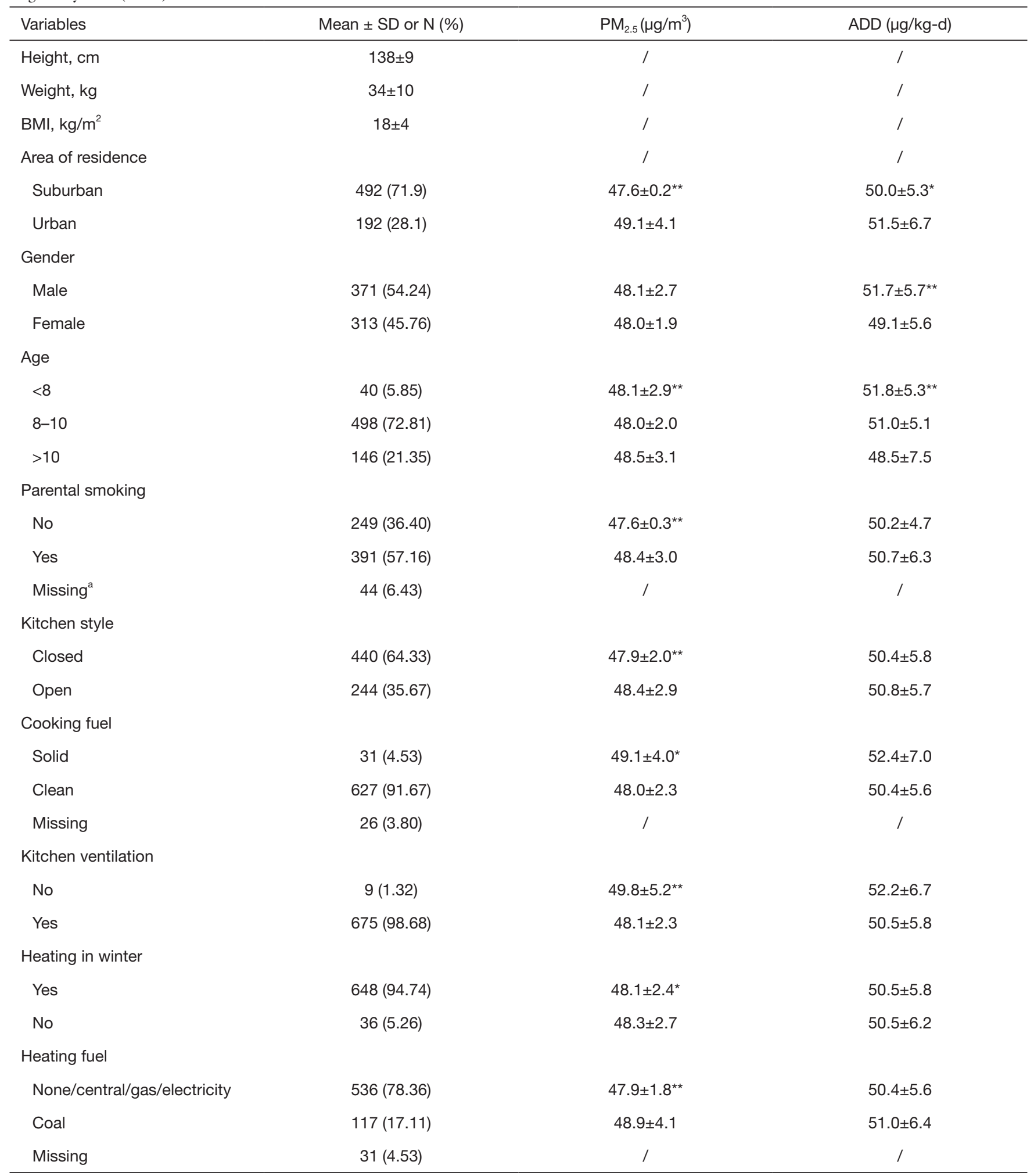

Table 1 (continued) 
Table 1 (continued)

\begin{tabular}{|c|c|c|c|}
\hline Variables & Mean \pm SD or $N(\%)$ & $\mathrm{PM}_{2.5}\left(\mu \mathrm{g} / \mathrm{m}^{3}\right)$ & ADD $(\mu \mathrm{g} / \mathrm{kg}-\mathrm{d})$ \\
\hline Yes & $150(21.93)$ & $48.3 \pm 3.3$ & $51.4 \pm 6.0^{*}$ \\
\hline No & $534(78.07)$ & $48.0 \pm 2.0$ & $50.3 \pm 5.7$ \\
\hline \multicolumn{4}{|l|}{ Asthma in past year } \\
\hline Yes & $8(1.17)$ & $48.1 \pm 0.3$ & $52.7 \pm 2.1$ \\
\hline \multicolumn{4}{|l|}{ Paternal education } \\
\hline Below senior high school & $326(47.66)$ & $48.2 \pm 2.9$ & $51.1 \pm 5.9^{*}$ \\
\hline Senior high school and above & $358(52.34)$ & $48.0 \pm 1.8$ & $49.9 \pm 5.6$ \\
\hline Senior high school and above & $337(49.27)$ & $47.9 \pm 1.6$ & $49.8 \pm 5.3$ \\
\hline \multicolumn{4}{|l|}{ Paternal asthma } \\
\hline No & 677 (98.98) & $48.1 \pm 2.4$ & $50.5 \pm 5.8$ \\
\hline Yes & $7(1.02)$ & $47.9 \pm 0.3$ & $49.9 \pm 4.6$ \\
\hline \multicolumn{4}{|l|}{ Maternal asthma } \\
\hline No & $680(99.42)$ & $48.1 \pm 2.4^{*}$ & $50.5 \pm 5.8$ \\
\hline Yes & $4(0.58)$ & $48.2 \pm 0.0$ & $54.5 \pm 3.3$ \\
\hline \multicolumn{4}{|l|}{ Fruit consumption } \\
\hline Above/with reference & 497 (72.66) & $47.9 \pm 2.0$ & $50.3 \pm 5.7$ \\
\hline Missing & $15(2.19)$ & / & / \\
\hline
\end{tabular}

${ }^{\mathrm{a}}$, the missing value of a variable; ${ }^{\mathrm{b}}$, fruit intake reference, once a day; ${ }^{\mathrm{c}}$, dairy intake reference, 5 to 6 times a week; ${ }^{* *}, \mathrm{P}<0.001 ;{ }^{*}, \mathrm{P}<0.05$.

adjusting the covariates resulted in losses of statistical significance for the ADD-PEF associations. After accounting for age, weight, height and gender, the ADD of long-term exposure of $\mathrm{PM}_{2.5}$ was associated with a $14.87 \mathrm{~mL}(95 \% \mathrm{CI}:-22.86$ to $-6.88, \mathrm{P}=0.0003)$ lower FVC and a $10.02 \mathrm{~mL}$ (95\% CI: -16.79 to $-3.25, \mathrm{P}=0.0039)$ lower $\mathrm{FEV}_{1}$. Children's exposure to indoor air pollution, socioeconomic status and parental history of asthma, children's infection of respiratory diseases recently, pre- birth (premature birth) and breast feeding were adjusted in model I. Nutrition and exercise related variables were further added in Model II. The ADD was still associated with a $10.49 \mathrm{~mL}(95 \% \mathrm{CI}:-20.47$ to $-0.50, \mathrm{P}=0.0402)$ lower FVC and a showed $7.68 \mathrm{~mL}$ (95\% CI: -15.80 to -0.44 , $\mathrm{P}=0.0386$ ) lower $\mathrm{FEV}_{1}$.

When we used 1-year averaged based ADD of $\mathrm{PM}_{2.5}$ for the year of lung function test [2017] and each of the previous 4 years, we observed generally similar patterns 
Table 2 Univariate analysis of possible influencing factors of lung function

\begin{tabular}{|c|c|c|c|c|}
\hline \multirow{2}{*}{ Variables } & $\mathrm{FVC}(\mathrm{mL})$ & $\mathrm{FEV}_{1}(\mathrm{~mL})$ & $\mathrm{PEF}(\mathrm{mL} / \mathrm{s})$ & $\mathrm{FEV}_{1} / \mathrm{FVC}(\%)$ \\
\hline & $\beta(95 \% \mathrm{Cl}) \mathrm{P}$ value & $\beta(95 \% \mathrm{Cl}) \mathrm{P}$ value & $\beta(95 \% \mathrm{Cl}) \mathrm{P}$ value & $\beta(95 \% \mathrm{Cl}) \mathrm{P}$ value \\
\hline Height & $\begin{aligned} 32.37 & (29.71,35.04) \\
& <0.0001\end{aligned}$ & $\begin{aligned} 29.31 & (27.10,31.53) \\
& <0.0001\end{aligned}$ & $51.42(44.29,58.55)<0.0001$ & $\begin{array}{c}0.01(-0.06,0.07) \\
0.8916\end{array}$ \\
\hline Weight & $\begin{aligned} 23.35 & (20.52,26.18) \\
& <0.0001\end{aligned}$ & $\begin{aligned} 19.89 & (17.42,22.35) \\
& <0.0001\end{aligned}$ & $33.10(26.04,40.17)<0.0001$ & $\begin{array}{c}-0.05(-0.11,0.01) \\
0.1323\end{array}$ \\
\hline BMI & $\begin{aligned} 27.64 & (19.88,35.40) \\
& <0.0001\end{aligned}$ & $\begin{aligned} 21.45 & (14.69,28.22) \\
& <0.0001\end{aligned}$ & $33.57(15.68,51.45) 0.0003$ & $\begin{array}{c}-0.15(-0.30,0.00) \\
0.0548\end{array}$ \\
\hline \multicolumn{5}{|l|}{ District } \\
\hline Urban (ref: suburban) & $\begin{array}{c}-90.9(-162.8,-19.0) \\
0.013\end{array}$ & $3.7(-58.8,66.2) 0.907$ & $155.5(-6.5,317.5) 0.060$ & $4.4(3.1,5.7)<0.001$ \\
\hline \multicolumn{5}{|l|}{ Gender } \\
\hline $\begin{array}{l}\text { Female } \\
\text { (ref: male) }\end{array}$ & $\begin{array}{l}-172.75(-236.57 \\
-108.92)<0.0001\end{array}$ & $\begin{array}{c}-134.69(-190.16,-79.21) \\
<0.0001\end{array}$ & $\begin{array}{c}-399.07(-542.48,-255.66) \\
<0.0001\end{array}$ & $\begin{array}{c}0.83(-0.38,2.05) \\
0.1794\end{array}$ \\
\hline \multicolumn{5}{|l|}{ Age (ref: 7 yr) } \\
\hline 8 & $\begin{array}{c}89.12(-45.23,223.48) \\
0.1940\end{array}$ & $\begin{array}{c}89.59(-23.75,202.93) \\
0.1218\end{array}$ & $\begin{array}{c}445.81(131.37,760.26) \\
0.0056\end{array}$ & $\begin{array}{c}0.76(-2.07,3.59) \\
0.5977\end{array}$ \\
\hline 9 & $\begin{array}{c}260.65(129.92,391.39) \\
0.0001\end{array}$ & $\begin{array}{c}234.36(124.07,344.64) \\
<0.0001\end{array}$ & $\begin{array}{c}665.90(359.93,971.86) \\
<0.0001\end{array}$ & $\begin{array}{c}0.48(-2.27,3.23) \\
0.7321\end{array}$ \\
\hline 10 & $\begin{array}{c}469.09(336.78,601.40) \\
<0.0001\end{array}$ & $\begin{array}{c}412.48(300.87,524.10) \\
<0.0001\end{array}$ & $\begin{array}{c}905.56(595.92,1,215.21) \\
<0.0001\end{array}$ & $\begin{array}{c}0.05(-2.74,2.83) \\
0.9732\end{array}$ \\
\hline 11 & $\begin{aligned} 612.07 & (475.35,748.79) \\
& <0.0001\end{aligned}$ & $\begin{aligned} 592.33 & (476.99,707.66) \\
& <0.0001\end{aligned}$ & $\begin{array}{c}1,337.57(1,017.59,1,657.56) \\
<0.0001\end{array}$ & $\begin{array}{c}2.20(-0.68,5.08) \\
0.1346\end{array}$ \\
\hline 12 & $\begin{aligned} 604.11 & (407.54,800.67) \\
& <0.0001\end{aligned}$ & $\begin{aligned} 569.18 & (403.37,735.00) \\
& <0.0001\end{aligned}$ & $\begin{array}{c}1,663.54(1,203.51,2,123.58) \\
<0.0001\end{array}$ & $\begin{array}{c}2.53(-1.61,6.67) \\
0.2315\end{array}$ \\
\hline
\end{tabular}

Parental smoking

Yes (ref: no)

Sleep in own room

No (ref: yes)

Sleep in own bed

No (ref: yes)

Kitchen style

Open (ref: closed)
$38.01(-29.67,105.69)$ 0.2714 0.0024

$-10.38(-69.52,48.76)$

0.7310

$60.37(-92.54,213.28) 0.43931 .58(0.30,2.85) 0.0157$ 0.1812
$-107.88(-177.39,-38.36)$
$-127.98(-192.22,-63.74)$ 0.0001
$-96.85(-152.61,-41.09)$
0.0007

$-176.99(-322.48,-31.49)$

0.0174

$0.60(-0.62,1.81)$

0.3357

Cook fuel

Clear (ref: solid)
$158.98(7.08,310.88) 0.0406$

$1.05(-0.21,2.31)$

0.1039 $94.56(-61.72,250.84)$
0.2361
$53.14(-82.21,188.49)$ 0.4419

Table 2 (continued) 
Table 2 (continued)

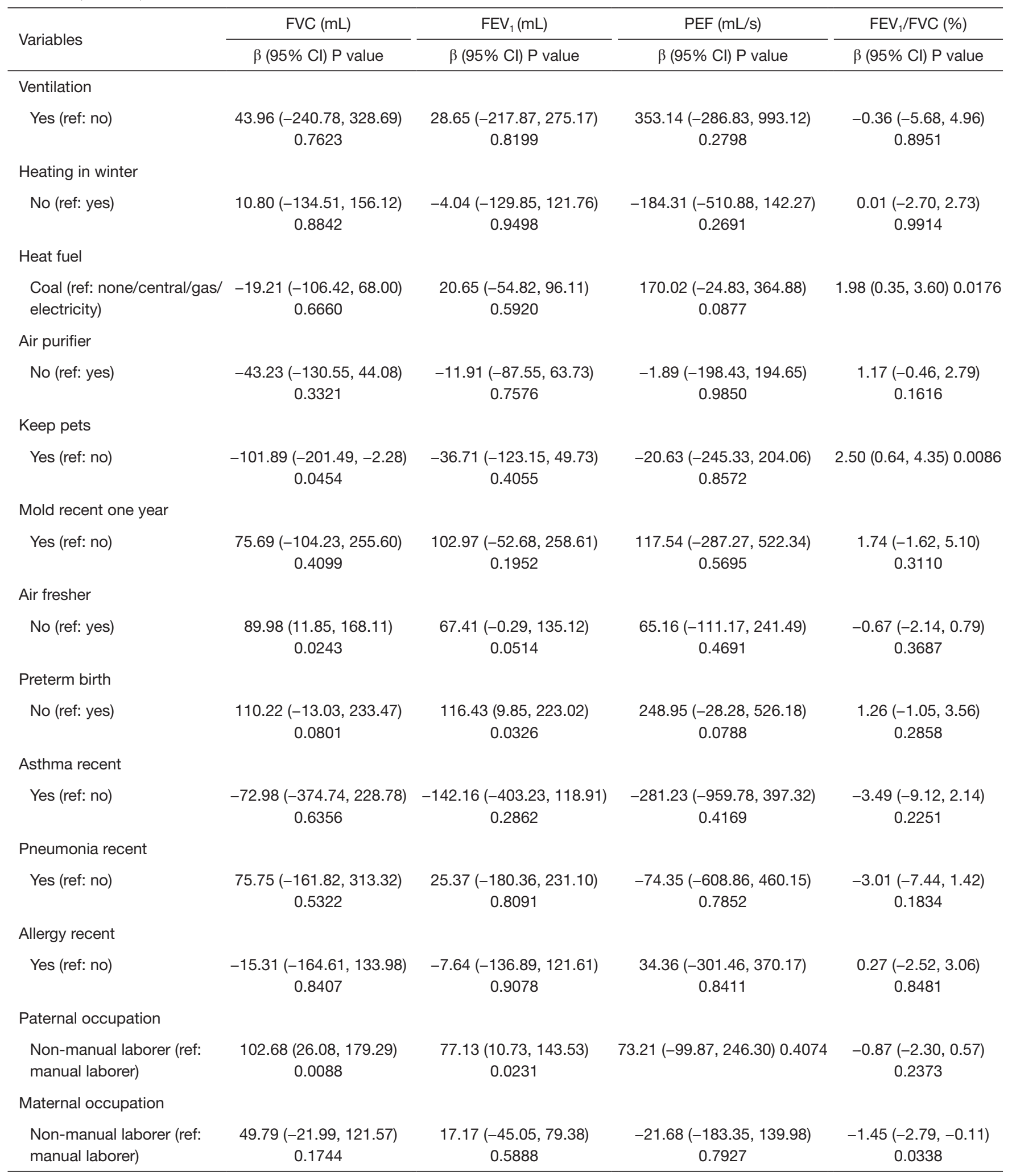

Table 2 (continued) 
Table 2 (continued)

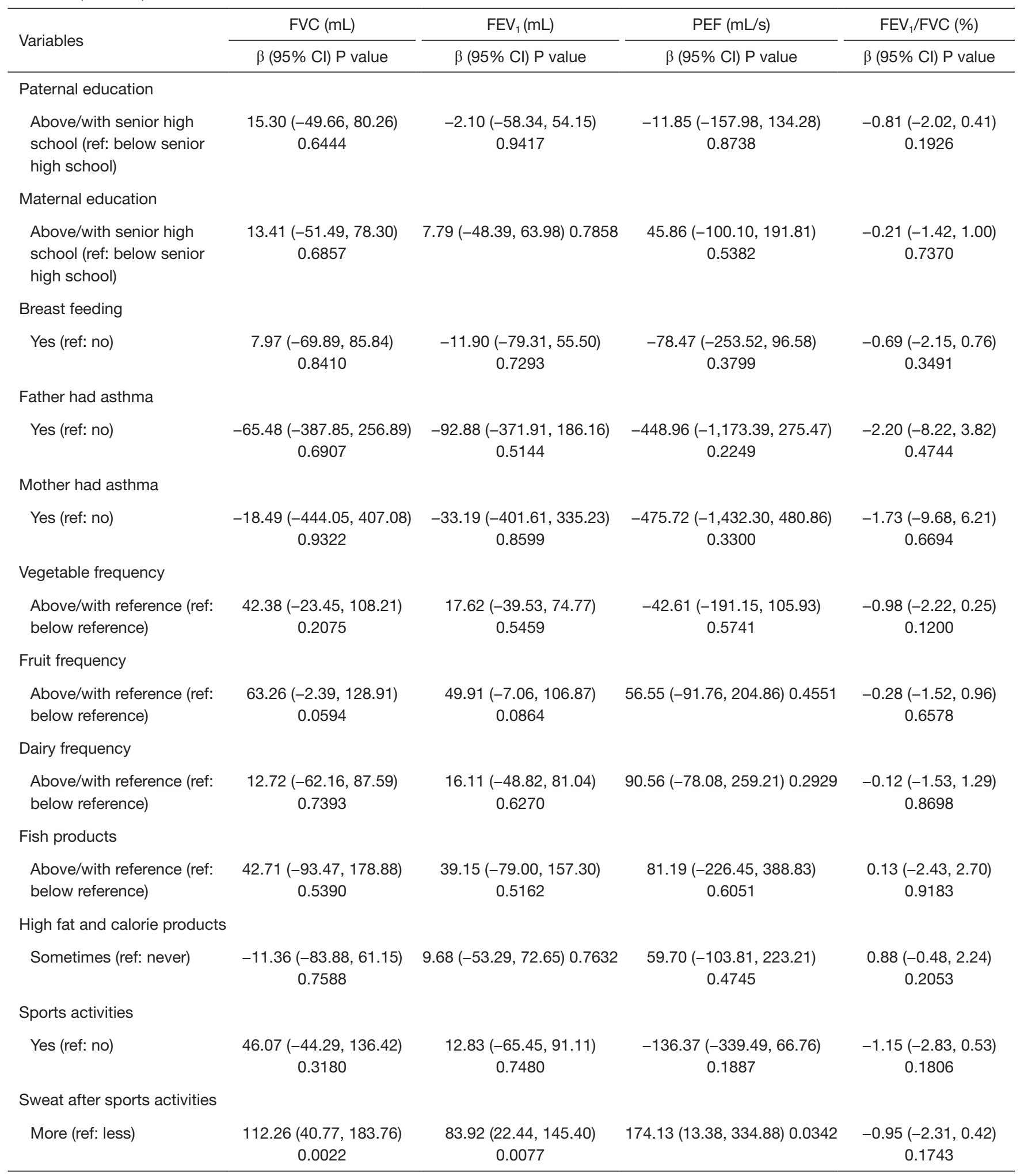




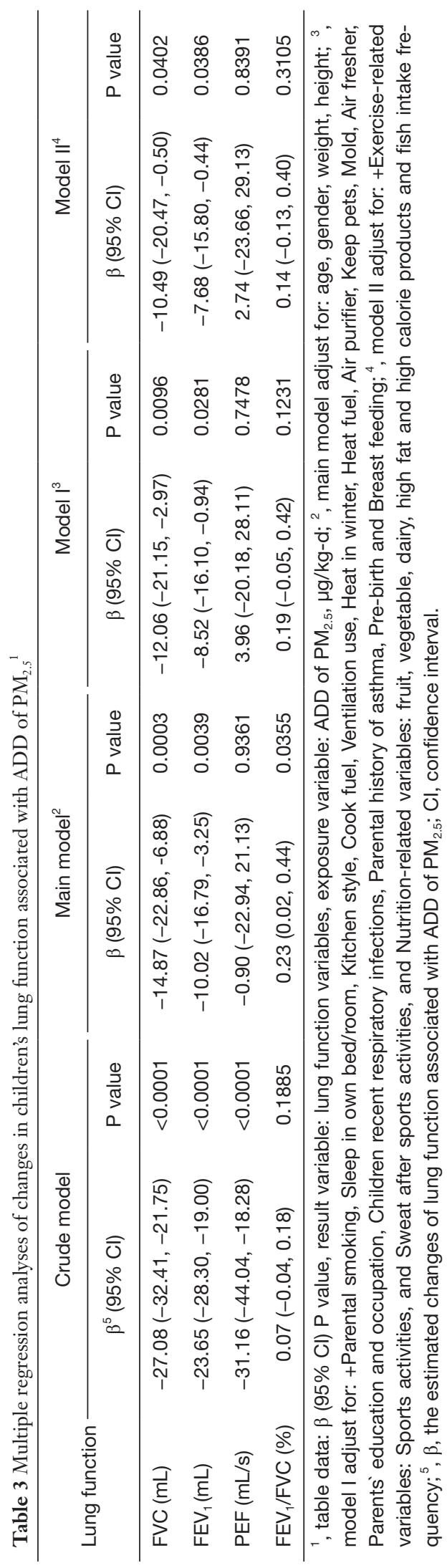

of ADD-lung function association (Figure 1). A closer examination showed that ADD averaged in 2016, 1-year prior of lung function measurement, had the strongest association with $\mathrm{FVC}$ and $\mathrm{FEV}_{1}$ in terms of both statistical significance and effect size, suggesting that exposure in the immediate past year may be most relevant to the $\mathrm{PM}_{2.5}$ effects in children.

When stratified the analyses by gender, we observed larger decreases in FVC and $\mathrm{FEV}_{1}$ associated with a unit increase in ADD in girls than in boys (Table S2). We also performed stratified analyses by district (urban $v$ s. suburban) (Table S3) and sweating after sports activities (less versus more) (Table S4). Larger decreases in FVC and $\mathrm{FEV}_{1}$ associated with a unit increase in ADD were found in suburban and less sweating after sports activities group. When replacing ADD with the 5-year average $\mathrm{PM}_{2.5}$ concentrations (calculated as time-weighted $\mathrm{PM}_{2.5}$ by Formula 2) in the same models (see Table S5), we observed no significant associations of $\mathrm{PM}_{2.5}$ concentrations with any of the lung function indictors including $\mathrm{FVC}$ and $\mathrm{FEV}_{1}$ that were significantly associated with $\mathrm{ADD}$ as described above. Considering no measurement data of indoor $\mathrm{PM}_{2.5}$ concentration, we referred to studies focused on indoor/ outdoor $(\mathrm{I} / \mathrm{O})$ ratio of $\mathrm{PM}_{2.5}$ performed in northern China $(37,38)$. Two reference values of $\mathrm{I} / \mathrm{O}(\mathrm{I} / \mathrm{O}=0.88 ; \mathrm{I} / \mathrm{O}=0.49)$ were selected to recalculated the concentration of individual $\mathrm{PM}_{2.5}$ and $\mathrm{ADD}$, then assess indoor $\mathrm{PM}_{2.5}$ exposure effects on lung function for sensitivity analysis (Table S6). Lung function is affected by indoor exposure to $\mathrm{PM}_{2.5}$ concentration and may have different effects with different I/O coefficients considered. Further research is needed to explore this relationship.

\section{Discussion}

In this study, we assessed individual-level $\mathrm{PM}_{2.5}$ exposure over the past 5 -year period. This long-term exposure, calculated as $\mathrm{ADD}$, was then related to lung function of children living in Lanzhou, China. The strengths of this study include the consideration of school and home address, the use of ADD to assess exposure, and detailed individual-level information on a suite of socioeconomic, parental health, and residential environmental conditions. The exposure dose (ADD) incorporated ambient $\mathrm{PM}_{2.5}$ concentration with individual's inhalation rate, duration of exposure and the average exposure time. $\mathrm{ADD}$, hence, is a more accurate indicator of individual-level exposure than concentration that has been commonly used. 

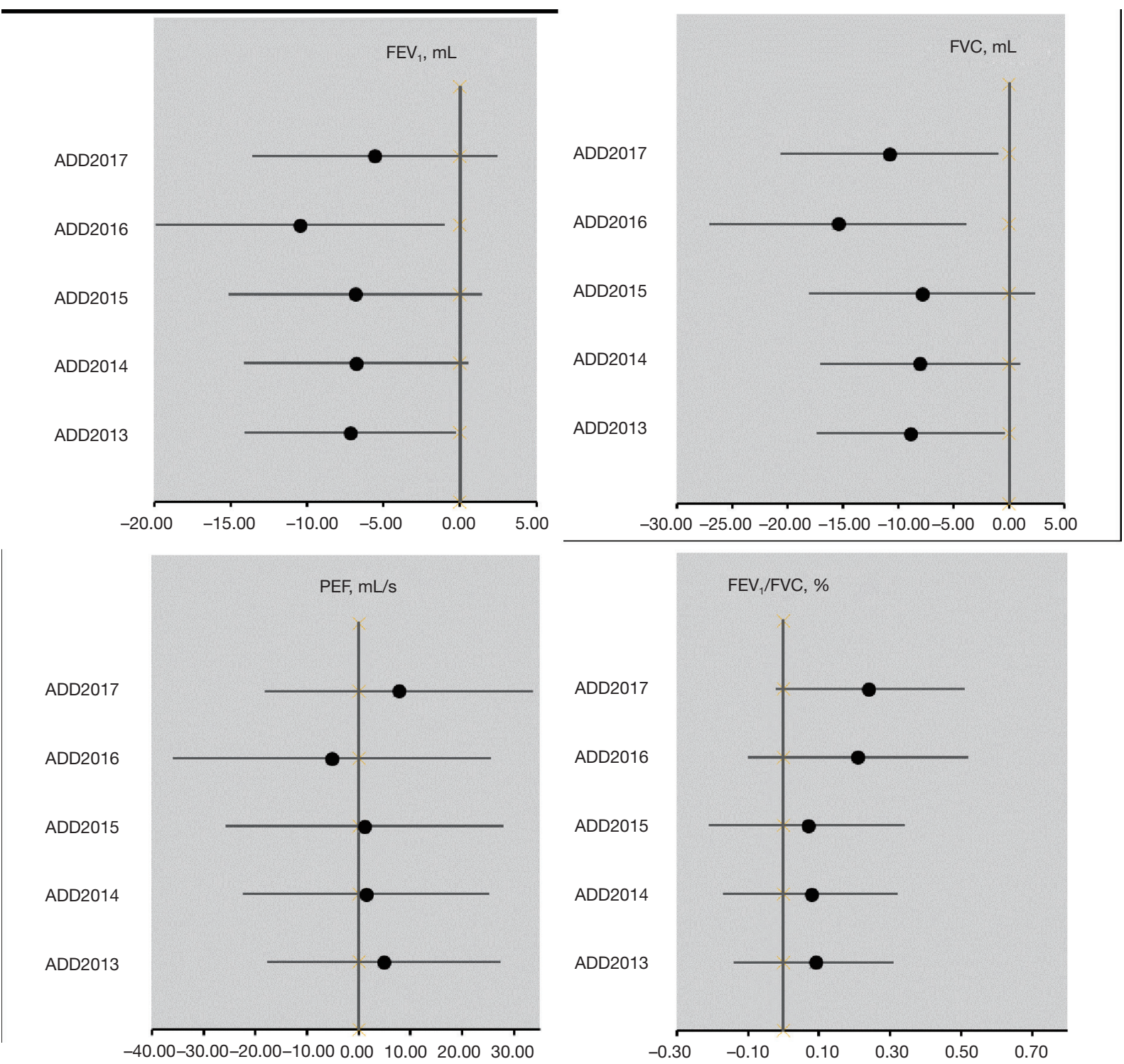

Figure 1 The effects of yearly average daily dose (ADD) on lung function.

Study subjects' average exposure to $\mathrm{PM}_{2.5}$ levels were estimated over a 5-year period, by assessing concentrations at different locations, including school, residence and the routes between residence and school. We described the $\mathrm{PM}_{2.5}$ level and ADD by subjects' attributes collected in a questionnaire survey. Results showed that $\mathrm{PM}_{2.5}$ levels differed by school/residence location, parental smoking, kitchen style, cook fuel, ventilation use, heating in winter and heating fuel type. Results showed that ADDs of $\mathrm{PM}_{2.5}$ differed by school/residence location, gender, and parental education attainment. Children living in the suburban area showed a significant lower $\mathrm{PM}_{2.5}$ and ADD levels in 2013-
2017, consistent with previous studies in Lanzhou (39-41).

The present study estimated the effects of annualaveraged ambient $\mathrm{PM}_{2.5}$ on lung function in a crosssectional study of primary school children, and found that increasing exposure levels were primarily associated with reductions in two major lung function indices (FVC and $\mathrm{FEV}_{1}$ ) examined in the study. Most previous studies have focused on $\mathrm{PM}_{2.5}$ concentration level in the air and the effects on lung function indices. The Framingham Heart Study (42) found negative associations with $\mathrm{FEV}_{1}$ and FVC (each $2 \mu \mathrm{g} / \mathrm{m}^{3}$ increase in $\mathrm{PM}_{2.5}$ was associated with a $13.5 \mathrm{~mL}$ lower $\mathrm{FEV}_{1}$ and $18.7 \mathrm{~mL}$ lower FVC), but not 
for the $\mathrm{FEV}_{1} / \mathrm{FVC}$ ratio. ESCAPE study (43) found an increase of $10 \mu \mathrm{g} / \mathrm{m}^{3}$ in $\mathrm{PM}_{10}$ was associated with a lower level of $\mathrm{FEV}_{1}(-44.6 \mathrm{~mL}, 95 \% \mathrm{CI},-85.4$ to -3.8$)$ and $\mathrm{FVC}$ $(-59.0 \mathrm{~mL}, 95 \% \mathrm{CI},-112.3$ to -5.6$)$, but not other PM metrics $\left(\mathrm{PM}_{2.5}\right.$, coarse fraction of $\mathrm{PM}, \mathrm{PM}$ absorbance).

To the best of our knowledge, our study is the first to use exposure dose in examining the effects of long-term ambient $\mathrm{PM}_{2.5}$ exposure on children's lung function. We are aware of only one previous study that used predicted average daily intake (ADD) of respirable PM (44), which found that the risk for having impaired respiratory function was 1.3 times greater in children with higher ADD due to living in industrial areas than those in the control group. In the present study, we only found significant associations of lung function with estimated $\mathrm{ADD}$ of $\mathrm{PM}_{2.5}$ but not with concentrations of $\mathrm{PM}_{2.5}$, after adjusting for individual information, indoor air pollution factors, and nutrition and exercise variables in the models.

Our findings are consistent with previous findings on the long-term $\mathrm{PM}_{2.5}$ effect on children's lung function or lung function growth. In a series of publications on lung function growth in Austrian schoolchildren, Ihorst et al. (45) and Horak et al. (46), reported on detected deficits in lung growth among children in highly polluted areas over a study period of 3.5 years. In the Californian Children's Health Study (CHS) (47), children living in the most polluted community had a growth deficit in $\mathrm{FEV}_{1}$ of approximately $100 \mathrm{~mL}$, as compared with those living in communities with better air quality over an 8 -year period. However, the adverse effect of $\mathrm{PM}_{2.5}$ on lung function was more pronounced by use of ADD, but not the concentration of $\mathrm{PM}_{2.5}$, in our study. A study in California showed that a pollutant-related delay in lung development in children can be attenuated if children move to cleaner geographic areas (48). In our study, the 5 -year average concentration level of $\mathrm{PM}_{2.5}$ was $48.1 \mu \mathrm{g} / \mathrm{m}^{3}$, and even the highest concentration in 2013 was $67 \mu \mathrm{g} / \mathrm{m}^{3}$, both of which meet the China's $\mathrm{PM}_{2.5}$ standard of $75 \mu \mathrm{g} / \mathrm{m}^{3}$. The concentration of fine PM was relatively low compared to other cities in developing countries, which may partly explain the discrepancy of the results in our study from previous researches. Additionally, in our study, the subjects are from two schools in a city. Age- and gender-weighted ADD can better reflect the exposure gradient, while the concentration gradient is smaller because the subjects live near the school. This might account for no significant associations of lung function with concentrations of $\mathrm{PM}_{2.5}$.

In our study, girls appeared to be more susceptible than boys to ambient $\mathrm{PM}_{2.5}$ exposure. Early studies found that negative associations between pollutants, including $\mathrm{PM}_{10}$, $\mathrm{PM}_{2.5}, \mathrm{NO}_{2}$, and $\mathrm{O}_{3}$, and the expiratory flow variables, including $\mathrm{FVC}, \mathrm{FEV}_{1}, \mathrm{PEF}, \mathrm{FEF} 25 \%$ and FEF $50 \%$, especially in girls $(49,50)$. Different gender*pollutant interaction effects occurring in different regions may be due to gender differences in hormonal factors and lung development physiology (51). There are gender disparities in the relationship between lung volume and flows (52), which might result in a gender-related response to air pollutants.

We found that the average daily exposure dose of $\mathrm{PM}_{2.5}$ in the year before the lung function test had the greatest effect on lung function. A large cohort study in the US investigated the association of air quality regulations in the 1990s, and lung function in 600 eight-year-old children. The authors found no significant associations between air pollution exposure and lung function, except for $\mathrm{PM}_{2.5}$ exposure one year before lung functional testing, and reduced $\mathrm{FEV}_{1}$ values (53). This weak association supports our findings, where we adjusted rigorously for potential confounders (e.g., living district, asthma status of the child), and found only associations of $\mathrm{FVC}$ and $\mathrm{FEV}_{1}$ one year before the lung function measurement within the overall population. For the lagging effect of PM on lung function, the analysis was done by reviewing previous studies and found that more attention had been paid to the short-term acute effect $(54,55)$, while fewer studies on the long-term effect can be referred to. Our study suggests that ADD may be used in future studies addressing the effects of long-term air pollution exposure.

However, there are limited references on the exposure window of $\mathrm{PM}_{2.5}$ affects lung function in children. The small reductions in lung function as reported in this and previous studies should encourage further reduction in ambient air pollution levels to protect susceptible children during vulnerable time windows of lung development. Furthermore, in order to prevent reporting spurious associations, studies should attempt to approximate exposure levels as precisely as possible, taking into account spatial and temporal variation, since factors such as proximity to major roads and shortterm air pollutant exposure are known to have an impact on individual exposure levels (56). To better evaluate the effects of improved air quality on children's health, more accurate exposure estimates are needed, especially in cases where air pollution changes rapidly over time.

This study has several limitations. Firstly, the indoor concentration is considered to be the same as the outdoor 
concentration, rather than actual measurements. We took into account the microenvironment (residence, school, and in-transit routes between school and residence) of the students and weighted concentration over time to be more consistent with the actual exposure levels, considering strong association between indoor and outdoor $\mathrm{PM}_{2.5}$ level (57). Also, we performed a sensitivity analysis by considering indoor/out (I/O) ratio of $\mathrm{PM}_{2.5}$. Further studies may develop a better understanding of individual exposure pathways in people's everyday lives by taking account of all environments in which people spend time to support health impact assessment. Secondly, we were unable to ascertain the role of other ambient air pollutants (such as sulfur dioxide and nitrogen dioxide) (58) played in the effects on lung function. This study mainly focuses on $\mathrm{PM}_{2.5}$. There should be future research on two-pollutant or multipollutant models to provide a better model fit when gaseous co-pollutants were adjusted for. Nevertheless, the present study demonstrated the usefulness of a new exposure assessment method (exposure dose at the individual level) in examining health effects of air pollution.

\section{Conclusions}

Long-term exposure to ambient $\mathrm{PM}_{2.5}$, estimated as $\mathrm{ADD}$, was associated with reduced lung function values of $\mathrm{FEV}_{1}$ and FVC in school children (7-12 years old) living in a typical industrial city located in northwestern China. Comparing the annual ADDs among the past 5 years, the value for the immediate past year prior to lung function measurements had the strongest associations. These findings suggest that accurate exposure estimates are needed where air pollution changes rapidly over time. These associations were stronger in girls than in boys. Using individual-level dose estimates, as opposed to exposure concentrations, is recommended for future studies of air pollution health effects, given that we observed no associations between $\mathrm{PM}_{2.5}$ concentrations (even at the individual level) and lung function.

\section{Acknowledgments}

We are particularly indebted to the children, their parents and the schools for their time and enthusiastic participation. We want to thank the $\mathrm{PM}_{2.5}$ concentration mapping of this work: Bin Zou, PhD, worked in School of Geosciences and InfoPhysics, Central South University. We also appreciate all those who helped me during the implementation of the project.

Funding: This work was supported by the National Science
Foundation (41977374) the National Key Research and Development Program of China (2016YFC1302501).

\section{Footnote}

Provenance and Peer Review: This article was commissioned by the Guest Editor (Junfengf Zhang, Howard Kipen and Haidong Kan) for the series "Children's Respiratory Health and Air Quality" published in Fournal of Thoracic Disease. The article was sent for peer review organized by the Guest Editors and the editorial office.

Data Sharing Statement: Available at http://dx.doi. org/10.21037/jtd-19-crh-aq-007

Conflicts of Interest: All authors have completed the ICMJE uniform disclosure form (available at http://dx.doi. org/10.21037/jtd-19-crh-aq-007). The series "Children's Respiratory Health and Air Quality" was commissioned by the editorial office without any funding or sponsorship. JJZ, HK and HK served as the unpaid Guest Editors of the series. JJZ also and serves as an unpaid editorial board member of Fournal of Thoracic Disease. The other authors have no other conflicts of interest to declare.

Ethical Statement: The authors are accountable for all aspects of the work in ensuring that questions related to the accuracy or integrity of any part of the work are appropriately investigated and resolved. The study was conducted in accordance with the Declaration of Helsinki (as revised in 2013). This study was reviewed and approved by the Committee on Ethics of Biomedicine Research, Duke Kunshan University, Jiangsu (No. FWA00021580). All patients enrolled completed the informed consent form.

Open Access Statement: This is an Open Access article distributed in accordance with the Creative Commons Attribution-NonCommercial-NoDerivs 4.0 International License (CC BY-NC-ND 4.0), which permits the noncommercial replication and distribution of the article with the strict proviso that no changes or edits are made and the original work is properly cited (including links to both the formal publication through the relevant DOI and the license). See: https://creativecommons.org/licenses/by-nc-nd/4.0/.

\section{References}

1. Xie R, Sabel CE, Lu X, et al. Long-term trend and spatial 
pattern of PM2.5 induced premature mortality in China. Environ Int 2016;97:180-6.

2. de Barros Mendes Lopes T, Groth EE, Veras M, et al. Pre- and postnatal exposure of mice to concentrated urban PM2.5 decreases the number of alveoli and leads to altered lung function at an early stage of life. Environ Pollut 2018;241:511-20.

3. Chu M, Sun C, Chen W, et al. Personal exposure to PM2.5, genetic variants and DNA damage: a multicenter population-based study in Chinese. Toxicol Lett 2015;235:172-8.

4. World Health Organization. Regional Office for Europe. Air quality guidelines: Global update 2005. Particulate matter, ozone, nitrogen dioxide and sulfur dioxide. Indian J Med Res 2007;4:492-3.

5. Health Effects Of Transport-related Air Pollution. Available online: https://www.euro.who.int/_data/assets/ pdf_file/0006/74715/E86650.pdf?ua=1

6. Adam M, Schikowski T, Carsin AE, et al. Effect of long-term exposure to traffic-related air pollution on lung function: The ESCAPE project. Eur Respir J 2013,42:P1549.

7. Chen C, Li C, Li Y, et al. Short-term effects of ambient air pollution exposure on lung function: A longitudinal study among healthy primary school children in China. Sci Total Environ 2018;645:1014-20.

8. Dubrowski A, Kliś K, Żurawiecka M, et al. Long-Term Exposure to Ambient Air Pollution in ChildhoodAdolescence and Lung Function in Adulthood. Adv Exp Med Biol 2019;1113:19-26.

9. Eriksson B, Lindberg A, Müllerova H, et al. Association of heart diseases with COPD and restrictive lung function--results from a population survey. Respir Med 2013;107:98-106.

10. Gehring U, Gruzieva O, Agius RM, et al. Air pollution exposure and lung function in children: the ESCAPE project. Environ Health Perspect 2013;121:1357-64.

11. McConnell R, Islam T, Shankardass K, et al. Childhood incident asthma and traffic-related air pollution at home and school. Environ Health Perspect 2010;118:1021-6.

12. Gauderman WJ, Gilliland GF, Vora H, et al. Association between air pollution and lung function growth in southern California children: results from a second cohort. Am J Respir Crit Care Med 2002;166:76-84.

13. Bergstra AD, Brunekreef B, Burdorf A. The effect of industry-related air pollution on lung function and respiratory symptoms in school children. Environ Health 2018;17:30.
14. Spyratos D, Sioutas C, Tsiotsios A, et al. Effects of particulate air pollution on nasal and lung function development among Greek children: a 19-year cohort study. Int J Environ Health Res 2015;25:480-9.

15. Casas M, den Dekker HT, Kruithof CJ, et al. The effect of early growth patterns and lung function on the development of childhood asthma: a population based study. Thorax 2018;73:1137-45.

16. Johnson M, Macneill M, Grgicak-Mannion A, et al. Development of temporally refined land-use regression models predicting daily household-level air pollution in a panel study of lung function among asthmatic children. J Expo Sci Environ Epidemiol 2013;23:259-67.

17. Gauderman WJ, Avol E, Gilliland F, et al. The effect of air pollution on lung development from 10 to 18 years of age. N Engl J Med 2004;351:1057-67.

18. Peters JM, Avol E, Gauderman WJ, et al. A study of twelve Southern California communities with differing levels and types of air pollution. II. Effects on pulmonary function. Am J Respir Crit Care Med 1999;159:768-75.

19. Majewska R, Pac A, Mróz E, et al. Lung function growth trajectories in non-asthmatic children aged 4-9 in relation to prenatal exposure to airborne particulate matter and polycyclic aromatic hydrocarbons - Krakow birth cohort study. Environ Res 2018;166:150-7.

20. Amadeo B, Robert C, Rondeau V, et al. Impact of closeproximity air pollution on lung function in schoolchildren in the French West Indies. BMC Public Health 2015;15:45.

21. Zeng XW, Vivian E, Mohammed KA, et al. Long-term ambient air pollution and lung function impairment in Chinese children from a high air pollution range area: The seven northeastern cities (SNEC) study. Atmos Environ 2016;138:144-51.

22. Jedrychowski WA, Perera FP, Maugeri U, et al. Long term effects of prenatal and postnatal airborne $\mathrm{PAH}$ exposures on ventilatory lung function of non-asthmatic preadolescent children. Prospective birth cohort study in Krakow. Sci Total Environ 2015;502:502-9.

23. Morales E, Garcia-Esteban R, de la Cruz OA, et al. Intrauterine and early postnatal exposure to outdoor air pollution and lung function at preschool age. Thorax 2015;70:64-73.

24. Schultz ES, Gruzieva O, Bellander T, et al. Traffic-related air pollution and lung function in children at 8 years of age: a birth cohort study. Am J Respir Crit Care Med 2012;186:1286-91.

25. Schultz ES, Hallberg J, Gustafsson PM, et al. Early life 
exposure to traffic-related air pollution and lung function in adolescence assessed with impulse oscillometry. J Allergy Clin Immunol 2016;138:930-2.e5.

26. Zhang Y, He M, Wu S, et al. Short-Term Effects of Fine Particulate Matter and Temperature on Lung Function among Healthy College Students in Wuhan, China. Int J Environ Res Public Health 2015;12:7777-93.

27. Guangzhou Statistics Bureau. Population distribution of Guangzhou in 2017 [Internet]. 2018. Available online: http://www.gzstats.gov.cn/gzstats/index.shtml

28. Miller MR, Hankinson J, Brusasco V, et al. Standardisation of spirometry. Eur Respir J 2005;26:319-38.

29. Quanjer PH, Stanojevic S, Cole TJ, et al. Multi-ethnic reference values for spirometry for the 3-95-yr age range: the global lung function 2012 equations. Eur Respir J 2012;40:1324-43.

30. Ferris BG. Epidemiology Standardization Project (American Thoracic Society). Am Rev Respir Dis 1978;118:1-120.

31. Fang X, Zou B, Liu X, et al. Satellite-based ground PM2.5 estimation using timely structure adaptive modeling. Remote Sens Environ 2016,186:152-63.

32. Xu S, Zou B, Lin Y, et al. Strategies of method selection for fine-scale PM2.5 mapping in an intra-urban area using crowdsourced monitoring. Atmos Meas Tech 2019;12:2933-48.

33. Zou B, Li S, Lin Y, et al. Efforts in reducing air pollution exposure risk in China: State versus individuals. Environ Int 2020;137:105504.

34. United States Environmental Protection Agency. Special Report on Lead Pollution [Internet] 2006. Available online: http://www.epa.gov/air/airtrends/lead.html

35. Ministry of environmental protection, Research report on environmental exposure behavior pattern of Chinese population (Children volume). 2013. Beijing: China environment press.

36. Wang SS, Lay S, Yu HN, et al. Dietary Guidelines for Chinese Residents (2016): comments and comparisons. J Zhejiang Univ Sci B 2016;17:649-56.

37. Zhang X, Chen B. Factors influencing indoor PM2.5 concentration in rural houses of northern China. IOP Conf Ser Earth Environ Sci 2018;121:032011.

38. Dai X, Liu J, Li X, et al. Long-term monitoring of indoor CO2 and PM2.5 in Chinese homes: Concentrations and their relationships with outdoor environments. Build Environ 2018;114:238-47.

39. Costabile F, Bertoni G, De Santis F, et al. Spatial Distribution of Urban Air Pollution in Lanzhou, China.
Open Environmental Pollution \& Toxicology Journal 2010;2:8-15.

40. Chu PC, Chen Y, Lu S, et al. Particulate air pollution in Lanzhou China. Environ Int 2008;34:698-713.

41. Sun W, Liu M, Yin Q, et al. Lanzhou air pollution change and management proposal in recent decades. Gansu Technology 2016;45:8-13.

42. Rice MB, Ljungman PL, Wilker EH, et al. Long-term exposure to traffic emissions and fine particulate matter and lung function decline in the Framingham heart study. Am J Respir Crit Care Med 2015;191:656-64.

43. Adam M, Schikowski T, Carsin AE, et al. Adult lung function and long-term air pollution exposure. ESCAPE: a multicentre cohort study and meta-analysis. Eur Respir J 2015;45:38-50.

44. Salami IR, As ZA, Marselina M, et al. Respiratory health risk assessment of children living close to industrial areas in Indonesia. Rev Environ Health 2014;29:139-42.

45. Ihorst G, Frischer T, Horak F, et al. Long- and mediumterm ozone effects on lung growth including a broad spectrum of exposure. Eur Respir J 2004;23:292-9.

46. Horak F Jr, Studnicka M, Gartner C, et al. Particulate matter and lung function growth in children: a 3-yr follow-up study in Austrian schoolchildren. Eur Respir J 2002;19:838-45.

47. Yamashita M, Yamashita M, Ando Y. A long-term followup of lung function in survivors of paraquat poisoning. Hum Exp Toxicol 2000;19:99-103.

48. Avol EL, Gauderman WJ, Tan SM, et al. Respiratory effects of relocating to areas of differing air pollution levels. Am J Respir Crit Care Med 2001;164:2067-72.

49. Rojas-Martinez R, Perez-Padilla R, Olaiz-Fernandez G, et al. Lung function growth in children with long-term exposure to air pollutants in Mexico City. Am J Respir Crit Care Med 2007;176:377-84.

50. Oftedal B, Brunekreef B, Nystad W, et al. Residential outdoor air pollution and lung function in schoolchildren. Epidemiology 2008;19:129-37.

51. de Marco R, Locatelli F, Sunyer J, et al. Differences in incidence of reported asthma related to age in men and women. A retrospective analysis of the data of the European Respiratory Health Survey. Am J Respir Crit Care Med 2000;162:68-74.

52. Schwartz J, Katz SA, Fegley RW, et al. Sex and race differences in the development of lung function. Am Rev Respir Dis 1988;138:1415-21.

53. Rice MB, Rifas-Shiman SL, Litonjua AA, et al. Lifetime Exposure to Ambient Pollution and Lung Function in 
Children. Am J Respir Crit Care Med 2016;193:881-8.

54. Chen BY, Chao HJ, Chan CC, et al. Effects of ambient particulate matter and fungal spores on lung function in schoolchildren. Pediatrics 2011;127:e690-8.

55. Min JY, Min KB, Cho SI, et al. Lag effect of particulate air pollution on lung function in children. Pediatr Pulmonol 2008;43:476-80.

56. Proietti E, Delgado-Eckert E, Vienneau D, et al. Air pollution modelling for birth cohorts: a time-space

Cite this article as: Li S, Cao S, Duan X, Zhang Y, Gong J, Xu X, Guo Q, Meng X, Bertrand M, Zhang JJ. Long-term exposure to PM2.5 and Children's lung function: a dose-based association analysis. J Thorac Dis 2020;12(10):6379-6395. doi: 10.21037/jtd-19-crh-aq-007 regression model. Environ Health 2016;15:61.

57. Meng QY, Spector D, Colome S, et al. Determinants of Indoor and Personal Exposure to $\mathrm{PM}(2.5)$ of Indoor and Outdoor Origin during the RIOPA Study. Atmos Environ (1994) 2009;43:5750-8.

58. Dales R, Kauri LM, Cakmak S, et al. Acute changes in lung function associated with proximity to a steel plant: a randomized study. Environ Int 2013;55:15-9. 


\section{Supplementary}

Table S1 Summary of lung function indicators and $\mathrm{PM}_{2.5}$ exposure

\begin{tabular}{|c|c|c|c|c|c|c|c|c|}
\hline Variables & $\mathrm{N}$ & Mean & SD & Min & P25 & P50 & P75 & Max \\
\hline FVC/predicted, \% & 898 & 104 & 10.7 & 52 & 83 & 93 & 102 & 223 \\
\hline $\mathrm{FEV}_{1} /$ predicted, \% & 898 & 102 & 9.7 & 49 & 83 & 92 & 101 & 225 \\
\hline PEF/predicted, \% & 898 & 77 & 0.8 & 26 & 63 & 77 & 91 & 144 \\
\hline \multicolumn{9}{|l|}{ Exposure estimates } \\
\hline $\mathrm{PM}_{2.5}, \mu \mathrm{g} / \mathrm{m}^{3}$ (5-yr average) & 613 & 48.1 & 0.10 & 43.8 & 47.6 & 47.7 & 48.1 & 69.1 \\
\hline ADD, $\mu \mathrm{g} / \mathrm{kg}-\mathrm{d}$ (5-yr average) & 613 & 50.5 & 0.23 & 26.3 & 46.7 & 50.9 & 54.1 & 76.2 \\
\hline $\mathrm{PM}_{2.5}$ in test year [2017] & 613 & 36.7 & 0.11 & 33.8 & 35.9 & 36.0 & 36.6 & 60.2 \\
\hline $\mathrm{PM}_{2.5}$ in 2014 & 613 & 51.8 & 0.11 & 47.0 & 51.5 & 51.5 & 51.6 & 75.9 \\
\hline $\mathrm{PM}_{2.5}$ in 2013 & 613 & 66.6 & 0.10 & 54.3 & 66.1 & 66.2 & 66.8 & 88.3 \\
\hline
\end{tabular}

Table S2 Multiple regression analyses of changes in children's lung function associated with ADD of $\mathrm{PM}_{2.5}{ }^{1}$ for boys and girls ${ }^{2}$

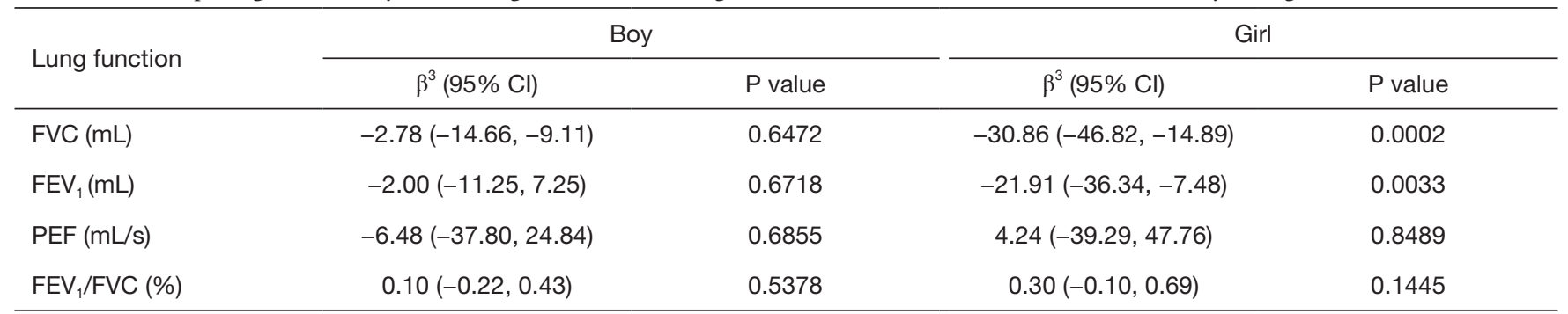

${ }^{1}$, table data: $\beta(95 \% \mathrm{Cl}) \mathrm{P}$ value, Result variable: lung function variables, Exposure variable: ADD of PM ${ }_{2.5}, \mu \mathrm{gg} / \mathrm{kg}-\mathrm{d} ;{ }^{2}$, adjust for: Age, Weight, Height, Parental smoking, Sleep in own bed/room, Kitchen style, Cook fuel, Ventilation use, Heat in winter, Heat fuel, Air purifier, Keep pets, Mold, Air fresher, Parents' education and occupation, Children recent respiratory infections, Parental history of asthma, Prebirth and Breast feeding, exercise-related variables and Nutrition-related variables; ${ }^{3}, \beta$, the estimated changes of lung function associated with $\mathrm{ADD}$ of $\mathrm{PM}_{2.5} ; \mathrm{Cl}$, confidence interval. 
Table S3 Multiple regression analyses of changes in children's lung function associated with ADD of $\mathrm{PM}_{2.5}{ }^{1}$, stratified analyses for urban and suburban $^{2}$

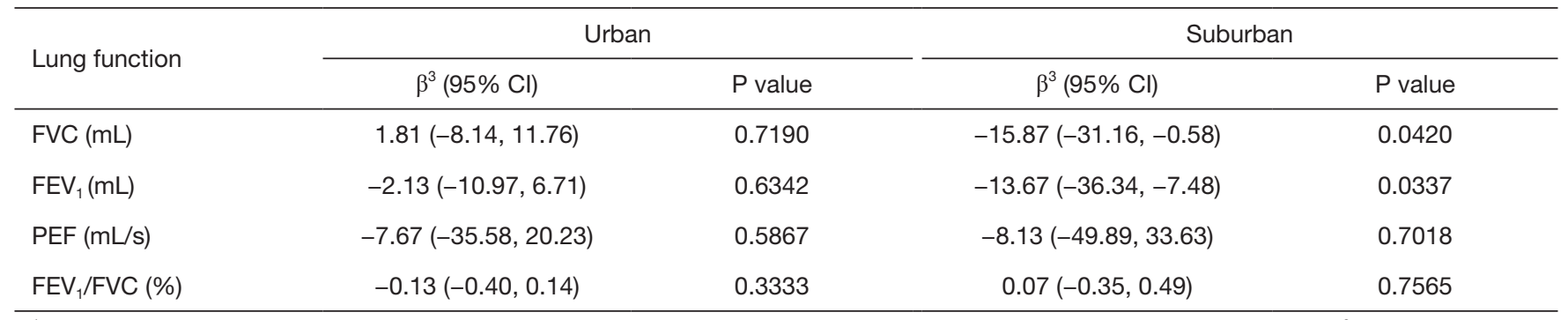

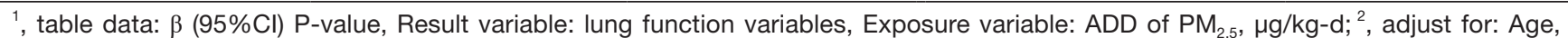
Weight, Height, Parental smoking, Sleep in own bed/room, Kitchen style, Cook fuel, Ventilation use, Heat in winter, Heat fuel, Air purifier, Keep pets, Mold, Air fresher, Parents' education and occupation, Children recent respiratory infections, Parental history of asthma, Prebirth and Breast feeding, exercise-related variables and Nutrition-related variables; ${ }^{3}, \beta$, the estimated changes of lung function associated with $\mathrm{ADD}$ of $\mathrm{PM}_{2.5} ; \mathrm{Cl}$, confidence interval.

Table S4 Multiple regression analyses of changes in children's lung function associated with ADD of $\mathrm{PM}_{2.5}{ }^{1}$, stratified analyses for less and more sweating after sports activities ${ }^{2}$

\begin{tabular}{lcccc}
\hline \multirow{2}{*}{ Lung function } & \multicolumn{2}{c}{ Less sweating } & \multicolumn{2}{c}{ More sweating } \\
\cline { 2 - 4 } & $\beta^{3}(95 \% \mathrm{Cl})$ & $\mathrm{P}$ value & $\beta^{3}(95 \% \mathrm{Cl})$ & $\mathrm{P}$ value \\
\hline FVC $(\mathrm{mL})$ & $-13.53(-26.40,-0.65)$ & 0.0396 & $-1.01(-14.30,12.28)$ & 0.8810 \\
FEV ${ }_{1}(\mathrm{~mL})$ & $-13.85(-24.92,-2.78)$ & 0.0145 & $-0.52(-10.94,9.89)$ & 0.9210 \\
PEF $(\mathrm{mL} / \mathrm{s})$ & $-14.15(-50.70,22.40)$ & 0.4458 & $8.09(-25.79,41.97)$ & 0.6382 \\
FEV 1 FVC $(\%)$ & $-0.06(-0.43,0.31)$ & 0.7507 & $0.07(-0.26,0.40)$ & 0.6800 \\
\hline
\end{tabular}

${ }^{1}$, table data: $\beta(95 \% \mathrm{Cl}) \mathrm{P}$ value, Result variable: lung function variables, Exposure variable: ADD of PM ${ }_{2.5}, \mu \mathrm{g} / \mathrm{kg}-\mathrm{d}$; ${ }^{2}$, adjust for: Age, Weight, Height, Parental smoking, Sleep in own bed/room, Kitchen style, Cook fuel, Ventilation use, Heat in winter, Heat fuel, Air purifier, Keep pets, Mold, Air fresher, Parents' education and occupation, Children recent respiratory infections, Parental history of asthma, Prebirth and Breast feeding, exercise-related variables and Nutrition-related variables; ${ }^{3}, \beta$, the estimated changes of lung function associated with $\mathrm{ADD}$ of $\mathrm{PM}_{2.5} ; \mathrm{Cl}$, confidence interval.

Table S5 Multiple regression analyses of changes in children's lung function associated with concentration of $\mathrm{PM}_{2.5}{ }^{1}$

\begin{tabular}{|c|c|c|c|c|c|c|c|c|}
\hline Lung function- & \multicolumn{2}{|l|}{ Crude model } & \multicolumn{2}{|l|}{ Main model ${ }^{2}$} & \multicolumn{2}{|l|}{ Model $\mathrm{I}^{3}$} & \multicolumn{2}{|l|}{ Model II ${ }^{4}$} \\
\hline $\mathrm{FVC}(\mathrm{mL})$ & $3.04(-10.99,17.07)$ & 0.6709 & $-8.52(-18.76,1.71)$ & 0.1032 & $-4.81(-15.64,6.03)$ & 0.3853 & $-1.29(-13.51,10.93)$ & 0.8362 \\
\hline $\mathrm{FEV}_{1}(\mathrm{~mL})$ & $5.34(-6.89,17.57)$ & 0.3921 & $-5.15(-13.79,3.50)$ & 0.2437 & $-3.77(-12.79,5.25)$ & 0.4129 & $-0.47(-10.39,9.46)$ & 0.9264 \\
\hline $\mathrm{PEF}(\mathrm{mL} / \mathrm{s})$ & $22.09(-9.89,54.07)$ & 0.1764 & $2.32(-25.67,30.30)$ & 0.8712 & $3.90(-24.71,32.50)$ & 0.7896 & $8.15(-23.96,40.26)$ & 0.6193 \\
\hline
\end{tabular}

${ }^{1}$, table data: $\beta(95 \% \mathrm{Cl}) \mathrm{P}$ value, Result variable: lung function variables, Exposure variable: concentration of $\mathrm{PM} \mathrm{M}_{2.5}, \mu \mathrm{g} / \mathrm{m}^{3} ;{ }^{2}, \mathrm{main} \mathrm{model}$ adjust for: Age, Gender, Weight, Height; ${ }^{3}$, model I adjust for: +Parental smoking, Sleep in own bed/room, Kitchen style, Cook fuel, Ventilation use, Heat in winter, Heat fuel, Air purifier, Keep pets, Mold, Air fresher, Parents' education and occupation, Children recent respiratory infections, Parental history of asthma, Pre-birth and Breast feeding; ${ }^{4}$, model II adjust for: +Exercise-related variables: Sports activities, and Sweat after sports activities, and Nutrition-related variables: fruit, vegetable, dairy, high fat and high calorie products and fish intake frequency; ${ }^{5}, \beta$, the estimated changes of lung function associated with concentration of $\mathrm{PM}_{2.5} ; \mathrm{Cl}$, confidence interval. 
Table S6 Multiple regression analyses ${ }^{1}$ of changes in children's lung function associated with ADD of $\mathrm{PM}_{2.5}$, a sensitivity analysis by considering indoor/outdoor (I/O) ratio of $\mathrm{PM}_{2.5}$

\begin{tabular}{lcccc}
\hline & \multicolumn{2}{c}{$\mathrm{I} / \mathrm{O}=0.88$} & & $\mathrm{l}=0.49$ \\
\cline { 2 - 3 } \cline { 5 - 6 } & $\beta^{3}(95 \% \mathrm{Cl})$ & $\mathrm{P}$ value & $\beta^{3}(95 \% \mathrm{Cl})$ & $\mathrm{P}$ value \\
\hline FVC $(\mathrm{mL})$ & $-8.66(-18.22,0.90)$ & 0.0757 & $-0.21(-2.91,2.50)$ & 0.8813 \\
FEV $(\mathrm{mL})$ & $-8.38(-16.19,-0.57)$ & 0.0354 & $-0.04(-2.27,2.20)$ & 0.9748 \\
PEF $(\mathrm{mL} / \mathrm{s})$ & $-5.71(-31.01,19.60)$ & 0.6578 & $-7.21(-14.27,-0.15)$ & 0.0452 \\
FEV $/$ FVC $(\%)$ & $0.03(-0.23,0.28)$ & 0.8244 & $0.01(-0.07,0.08)$ & 0.8959 \\
\hline
\end{tabular}

', adjust for: Age, Weight, Height, Parental smoking, Sleep in own bed/room, Kitchen style, Cook fuel, Ventilation use, Heat in winter, Heat fuel, Air purifier, Keep pets, Mold, Air fresher, Parents' education and occupation, Children recent respiratory infections, Parental history of asthma, Pre-birth and Breast feeding, exercise-related variables and Nutrition-related variables. 